\title{
Evaluation of the Karst Water Quality Upstream of Junhe River Basin in Shandong Province, China
}

\author{
Mingyi REN \\ School of Resources and Environment \\ University of Jinan \\ Jinan 250022, China \\ e-mail: ren_mingyi@126.com \\ Jiezhong WANG \\ School of Resources and Environment \\ University of Jinan \\ Jinan 250022, China \\ e-mail: aking_wjz@163.com
}

\author{
Liyuan YANG \\ School of Resources and Environment \\ University of Jinan \\ Jinan 250022, China \\ e-mail: youngliyuan@126.com \\ Chunhua LIU \\ Shandong Institute of Geological Survey \\ Jinan 250013, China \\ e-mail: chunhua_liu321@126.com
}

\begin{abstract}
Seventy nine karst water samples were used to study the quality of groundwater in upstream of Junhe River. The main hydrochemical types were $\mathrm{HCO}_{3}$ type, $\mathrm{HCO}_{3} \cdot \mathrm{SO}_{4}$ type, $\mathrm{HCO}_{3}{ }^{\circ} \mathrm{Cl}$ type and $\mathrm{Cl}$ type, and the $\mathrm{HCO}_{3}$ type occupied $58 \%$ of the total evaluation area. The sample points were grouped in the lower-left corner of the Piper picture, showing that the content of alkaline-earth metal ions exceeded that of alkali metal ions and weak acid ions exceeded the strong acid ions. The Schoeller picture demonstrated that the karst water originated from the same recharge source that was precipitation and the connectedness in the area was well. Groundwater comprehensive quality evaluation showed that most samples were at level IV. Karst water pollution in evaluation area was serious, and it was urgent to improve the quality of groundwater.
\end{abstract}

Keywords-Junhe Rive; karst water; quality evaluation

\section{INTRODUCTION}

Junhe river upstream basin is located among the mountainous regions in the middle of Shandong, which is lack of groundwater resources, and the karst water is the important water supply sources in this area. So the quality of karst water has a huge impact on the economic development and the lives of local residents. With the development of economy, the demand for water resources grows bigger and bigger, so the contradiction between groundwater supply and demand in this area is increasingly prominent ${ }^{[1]}$. Recently, there is a worsening tendency for the karst water environment simultaneously. Hence, it's urgent to evaluate the karst water quality of Junhe river upstream basin. The majority supply condition in evaluation area was precipitation, which is relative simple. The precipitation in 2013 was $705.9 \mathrm{~mm}$, which was relatively abundant.

\section{METHODS}

Nemero comprehensive index method can fully reflect the comprehensive quality of groundwater. Detailed evaluation steps are as follows:
(1) Individual components evaluation and comprehensive evaluation of water samples are made based on water quality analysis data. Individual component evaluation is divided into five categories based on groundwater quality standard classification index. In table $\mathrm{I}$, evaluation score $\left(\mathrm{F}_{\mathrm{i}}\right)$ is assigned to each single component, then comprehensive evaluation score can be calculated.

TABLE I. CONVERSION BETWEEN GROUNDWATER WATER QUALITY CATEGORIES AND FI.

\begin{tabular}{cccccc}
\hline category & I & II & III & IV & V \\
\hline$F_{i}$ & 0 & 1 & 3 & 6 & 10 \\
\hline & & \multicolumn{3}{c}{$n$ nis the number of evaluation index }
\end{tabular}

(2) Calculate the average value of a single component score (Fi), as in Eq. (1).

$$
\overline{\mathrm{F}}=\frac{1}{\mathrm{n}} \sum_{\mathrm{i}=1}^{\mathrm{n}} \mathrm{F}_{\mathrm{i}}
$$
(2).

(3) Calculate the comprehensive evaluation value, as in Eq.

$$
\mathrm{F}=\sqrt{\frac{\overline{\mathrm{F}}^{2}+\mathrm{F}_{\mathrm{max}}^{2}}{2}}
$$

(4) In table II, we can divide the comprehensive quality of groundwater level based on $\mathrm{F}$ value.

TABLE II. COMPARISON BETWEEN WATER QUALITY EVALUATION AND COMPREHENSIVE CLASSIFICATION

\begin{tabular}{cccccc}
\hline category & I & II & III & IV & V \\
\hline F & $<0.80$ & $0.80-2.50$ & $2.50-4.25$ & $4.25-7.20$ & $\geq 7.2($ \\
\hline \multicolumn{5}{c}{$\mathrm{F}_{\max }$ is the max value of single component score } \\
\hline \multicolumn{6}{r}{. }
\end{tabular}




\section{RESULTS AND DISCUSSION}

\section{A. Karst Water Chemical Analysis}

79 deep phreatic water samples from the evaluation area were selected to study the chemical characteristics of groundwater from the upstream of Junhe river basin.

According to results of the Shug Kalev classification method, there were four main anions types of groundwater in Junhe river evaluation area, including $\mathrm{HCO}_{3}$ type, $\mathrm{HCO}_{3} \cdot \mathrm{SO}_{4}$ type, $\mathrm{HCO}_{3} \cdot \mathrm{Cl}$ type and $\mathrm{Cl}$ type. The $\mathrm{HCO}_{3}$ type occupied larger area, the distribution area was about 58\% proportion of the total evaluation area. The main cation types were Ca type and $\mathrm{Ca} \cdot \mathrm{Mg}$ type, and the distribution area of Ca type was $69 \%$ of the total evaluation area. However, the distribution area of $\mathrm{Ca} \bullet \mathrm{Mg}$ type was small.

There was a certain causal relationship between the groundwater chemical and continent monsoon climate in Junhe river basin. The overwhelming majority rocks in evaluation area were carbonate rocks, and Quarternary lied in front of surrounding mountains and in the cheuch, and the thickness of quarternary was relative thin. The groundwater chemical ingredients exist in the atmosphere long time ago, the present groundwater chemical ingredients were the product under the synthetic action of evaporation, water-rock interaction in aetation zone, lixiviation and continental salinization. Lixiviation was beneficial to produce the small mineralization groundwater, which was $\mathrm{HCO}_{3}{ }^{\circ} \mathrm{Ca}$ type. The high mineralization $\mathrm{HCO}_{3}{ }^{\circ} \mathrm{Cl}$ type was general located in low elevation, weak evaporation area.

The piper was applied to study the groundwater samples. The analysis results indicated that the sample points grouped in some regions, which confirmed that the groundwater chemical ingredients endured the same climate effect. Some points were scattered, which reflect the differentiation effect of wate-bearing media hydrodynamic force conditions. In addition, karst fissuring groundwater samples focused in supply region and accept the direct precipitation[2]. The features in this area were that evaporation and concentration roles were weak and lixiviation role was also weak. In fig 1 , we could easily find that, on the one hand, the content of alkaline-earth metal ions in groundwater exceeded that of alkali metal ions in the evaluation area, on the other hand, weak acid ions exceeded the strong acid ions.

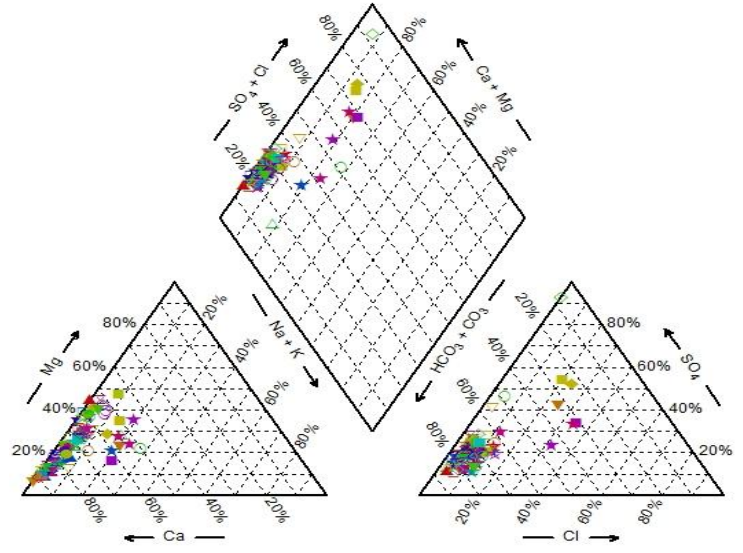

Figure 1. Karst water piper in evaluation area.

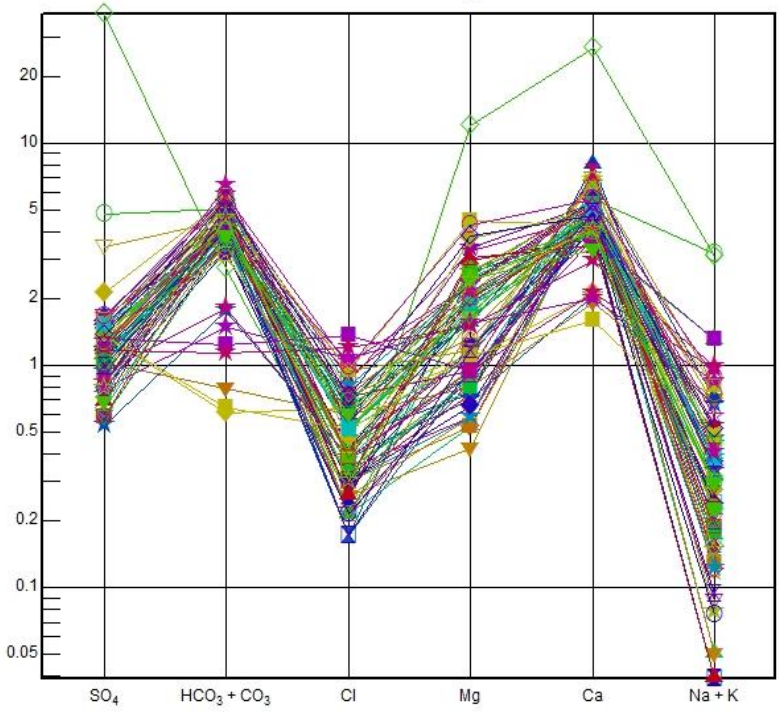

Figure 2. Karst water Schoeller in evaluation area.

The Schoeller picture could be used to study the fluctuation in different samples of groundwater chemical components. The concentration of components could be lined to a curve, and the same concentration samples wouldn't vary shape along with the vertical shift of curves. In fig 2, the vary characters of ions content were basically same. This demonstrated most groundwater in evaluation area had the same supply, and the relationship between different groundwater samples were relatively close. Simultaneously, this demonstrated the connectedness in the area was well.

\section{B. Groundwater Quality Evaluation}

Mastering the groundwater quality state, and identifying the pollution source not only could assist to develop and utlize karst groundwater, but also had significance to prevent groundwater pollution[3]. Consequently, it was urgent to make a comprehensive groundwater quality evaluation in Junhe river upstream basin.

The Nemero comprehensive index method was adopted as the groundwater quality comprehensive evaluation method with regard to the karst water conditions, and the evaluation index refer to Quality standard for ground water (GB/T14848-93). The evaluation items were total hardness, $\mathrm{pH}$, permanganate index, $\mathrm{NH}_{4}{ }^{+}, \mathrm{NO}_{3}{ }^{-}, \mathrm{NO}_{2}{ }^{-}, \mathrm{As}, \mathrm{Hg}, \mathrm{Pb}, \mathrm{Fe}$, $\mathrm{Cd}, \mathrm{Se}, \mathrm{Mn}, \mathrm{SO}_{4}^{2-}, \mathrm{Cr}^{6+}, \mathrm{F}^{-}, \mathrm{I}^{-}$and $\mathrm{Cl}^{-}, 18$ items in all ${ }^{4]}$. 


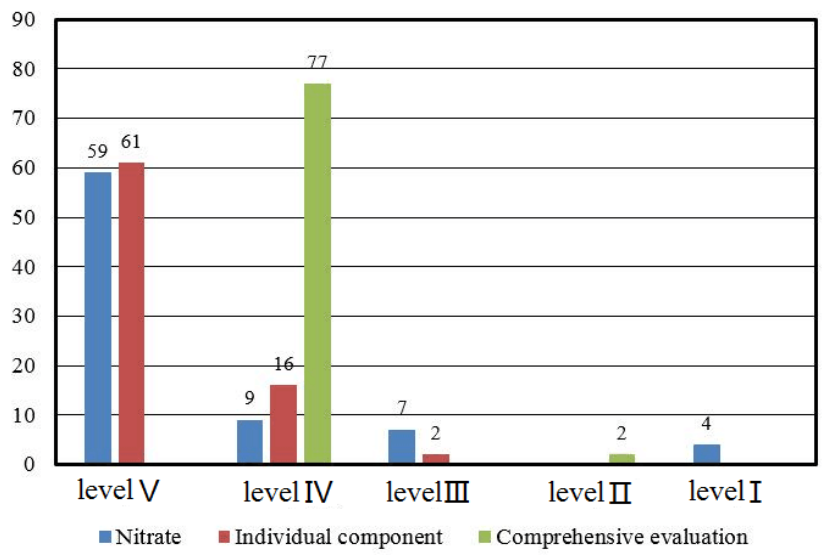

Figure 3. Karst water quality analysis.

According to the groundwater quality comprehensive evaluation results of 79 groundwater samples in the research area, the quality of groundwater was relatively poor. According to Quality standard for ground water (GB/T14848-93), there were 77 groundwater samples which were at level IV, which could be used to irrigation and industrial purposes partly, and they were mainly distributed in the river valley of Junhe. Only two groundwater samples were at level II, which were distributed around Zhutian river, a tributary of Junhe river, and the quality was good. Overall, the karst water quality was less well.

In the individual components of evaluation, 61 groundwater samples were at level V, 16 were at level IV, and 2 were at level III. The results of nitrate factor evaluation showed that, most groundwater samples were at level $\mathrm{V}$ and IV. SPSS were adopted to analyze the correlativity of nitrate, individual component and comprehensive evaluation. On the basis of the results, the Pearson correlativity between individual component and nitrate was 57.5\%, and the Pearson correlativity between individual component and comprehensive evaluation was $63.86 \%$. Therefore, the nitrate had a heavy influence on the groundwater comprehensive quality. However, most nitrate came from chemical fertilizer that was used to raise production by farmers[5]. In addition, the karst in the study area had a good connectivity and rock cranny overgrown, which could be propitious to groundwater movement and store. Hence, the karst groundwater was generally polluted by nitrate. The research showed that some necessary and relative measures must be implemented to supervise nitrate fertilizer application and curb the karst water pollution.

\section{CONCLUSION}

The sample points in Piper picture grouped in the lower-left corner of the study area, showing that the content of alkaline-earth metal ions in exceeded that of alkali metal ions and weak acid ions exceeded the strong acid ions. The Schoeller picture demonstrated that the karst water originated from the same recharge source that was precipitation and the connectedness in the area was well. According to the results of groundwater quality evaluation, karst water pollution in upstream of Junhe river was serious, and some necessary measures must be put into practice to improve the quality of groundwater.

\section{ACKNOWLEDGMENTS}

This research was financially supposed by the regional hydro-geological survey Projects of Shandong Province (Shandong Survey No. (2012) 28).

\section{REFERENCES}

[1] Su Yaoming, Su Xiaosi. Present situation and prospecting of groundwater quality evaluation. Water Resources Protection. Vol. 23 (2007) No. 02, p. 4-12.

[2] Li Yanjun, Yang Muzhuang. A Review of Groundwater Quality Evaluation Methods. Ground water. Vol. 29 (2007) No. 05, p. 19-24.

[3] Li Junxia, Su Chunli, Xie Xianjun, et al. Application of Multivariate Statistical Analysis to Research the Environment of Groundwater: A Case Study at Datong Basin, Northern China. Geological Science and Technology Information. Vol. 29 (2010) No. 06, p. 94-100.

[4] Wang Hongjin, Pang Xugui, He Yuhai, et al. Environmental Quality Evaluation and Analysis of Shallow Ground Water in Linyi City. Journal of Anhui Agriculture Science. Vol. 42 (2012) No. 05, p. 1474-1476.

[5] Lin Haitao, Jiang Lihua, Song Xiaozong. Nitrate Concentration of Groundwater and Its Affecting Factors in Shandong Province, China Journal of Agro-Environment Science. Vol. 30 (2011) No. 02, p. 353-357. 